\title{
Thermal volume changes of saturated sand during loading- unloading-heating phase
}

\author{
Hong Liu ${ }^{1}$, John S. McCartney ${ }^{2}$, Yang Xiao ${ }^{3 *}$ \\ ${ }^{1}$ School of Architectural Engineering, Neijiang Normal University, Sichuan, 641100, China. \\ ${ }^{2}$ Department of Structural Engineering, University of California San Diego, 9500 Gilman Drive, La Jolla, CA, 92093-0085, USA. \\ ${ }^{3}$ School of Civil Engineering, Chongqing University, Chongqing, 400045, China.
}

\begin{abstract}
The influence of temperature on the volume change of loose, saturated sand was assessed through a series of temperature-controlled hollow-cylinder triaxial tests. The sand specimens were isotropically compressed and unloaded to induce an overconsolidation effect, then subjected to drained heating. During drained heating, water was expelled from the sand specimens and the thermally-induced axial and volumetric strains were negative, reflecting isotropic expansion.
\end{abstract}

\section{Introduction}

Ground Source Heat Pump (GSHP) systems are an important technology in the global effort to develop sustainable and renewable energy systems. This technology uses a heat pump and a closed-loop heat exchanger buried underground to transfer thermal energy between the ground and an overlying structure. On this basis, a series of energy geo-structures have been successfully designed to operate within the very shallow part of the ground in many countries, such as Europe [1], Australia [2], UK [3], United States [4, 5] and China [6, 7]. There are a range of energy geo-structures proposed in the literature, including energy piles $[1,3,6,9-11]$, energy retaining walls [8], energy tunnel linings [12], energy embankments [13] and energy pavements for highways [14, 15]. Heating and cooling of the soil during operation of these energy geo-structures may contribute to movements or changes in stress due to the thermal expansion and contraction of the structural elements or surrounding soil.

In all the geo-structure applications noted above, temperature-controlled element-scale tests on soils are needed to understand the thermo-mechanical response of the soils during changes in stress or temperature. Different from other engineering materials like steel or concrete, changes in temperature may induce contraction or expansion of soils. In the case of energy piles, soil volume changes may affect the shaft resistance of pile and settlement. The volume change behavior of saturated clays and silts under drained heating or temperature cycle have been thoroughly evaluated in several studies [13, 16-24]. A common viewpoint was demonstrated that the thermal volume change of saturated clay during drained heating changes from contractive to expansive behavior with increasing over-consolidation ratio (OCR) [13, 16, 18, 20, 25]. In the case of some of the energy geo-structures mentioned above, high thermal conductivity backfill materials such as sands are used [26].

Although it is thus critical to understand the thermal volume change of sands, only limited studies have been performed on saturated sands. For example, $\mathrm{Ng}$ et al. [26] found that loose $\left(D_{\mathrm{r}}=21 \%\right)$ and medium-dense $\left(D_{\mathrm{r}}=70 \%\right.$ ) sand specimens reflected contraction when the temperature increased from $23{ }^{\circ} \mathrm{C}$ to $35^{\circ} \mathrm{C}$, while reflected expansion as the temperature raised up to $50^{\circ} \mathrm{C}$. In addition, larger mean effective stress may lead to higher thermal volumetric strains. However, dense sand specimens ( $D_{\mathrm{r}}=90 \%$ ) only occurred thermal expansion and did not observe major impact of mean effective stress on their volume changes which were found by Liu et al. [27]. Test results from Liu et al. [27] indicated the thermal volume change behaviors of sands depended on the relative density and underwent a translation from contraction into expansion with increasing relative density.

The main objective of this paper is to evaluate the thermal volume change of loose, saturated sand specimens through a series of temperature-controlled hollow triaxial compression tests. Variables measured include the volume of water expelled during mechanical loading phase, mechanical unloading phase and drained

\footnotetext{
* Corresponding author: hhuxyanson@163.com
} 
heating phase. In addition, the effects of temperature on axial and volumetric strains of saturated sand specimens are also described. Loose sands may be encountered in thermal backfill around heat exchanger pipes in boreholes, or loosely placed material in energy embankments where compaction is not thorough.

\section{Testing program}

A series of temperature-controlled hollow triaxial compression tests were carried out on reconstituted specimens of sand obtained from Fujian located on the southeast coast of China. The main component of this sand is $\mathrm{SiO}_{2}$, approximately $96 \%$. The particle shape is angular/subangular with the maximum particle size of 2 $\mathrm{mm}$. in the particle size distribution for this sand is shown in Figure 1. This material has a medium particle size $D_{50}$ of $0.60 \mathrm{~mm}$, a maximum void ratio $e_{\max }$ of 0.708 and a minimum void ratio $e_{\min }$ of 0.335 . The uniformity coefficient $C_{\mathrm{u}}$ and coefficient of curvature $C_{\mathrm{c}}$ have been calculated as 7.05 and 0.54 . This material is classified as poorly graded sand (SP) according to the Unified Soil Classification System [28].

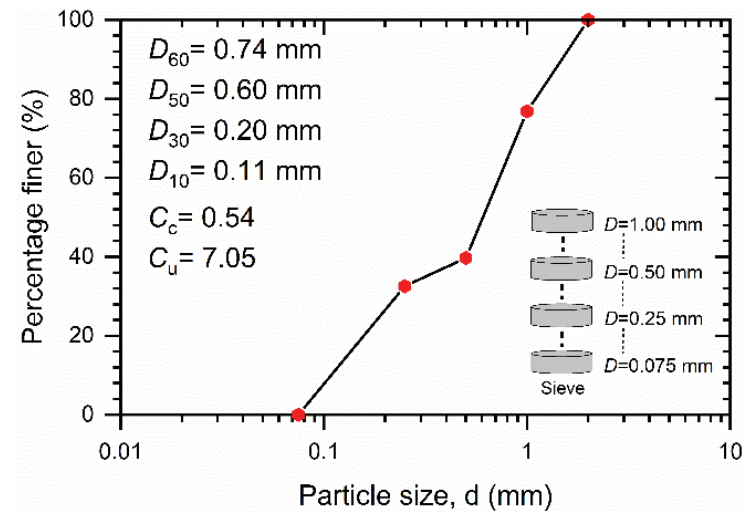

Fig. 1. Particle size distribution for Fujian sand

A conventional hollow triaxial apparatus obtained from GCTS was modified to estimate the thermal mechanical behavior of saturated soils [27]. The outer diameter, inner diameter and height of the hollow cylinder specimens are equal to $100 \mathrm{~mm}, 60 \mathrm{~mm}$ and 200 $\mathrm{mm}$, respectively. This loose specimen $\left(D_{\mathrm{r}}=10 \%\right)$ was prepared using the moist tamping method in which dry sand particles were premixed with de-aired water to a gravimetric water content of approximately $5 \%$, and placed in a minimum of eight layers within a neoprene membrane surrounded by the mold. To obtain the same target height, each layer was gently compacted using a flat-bottom tamper.

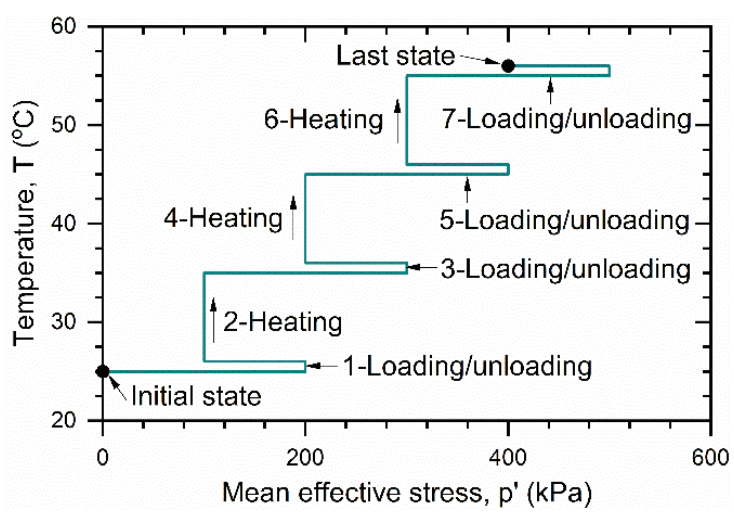

Fig. 2. Stress paths for Fujian sand

After saturation, a mechanical loading-unloading cycle up to $200 \mathrm{kPa}$ and back to $100 \mathrm{kPa}$ was carried out under a constant temperature of $25{ }^{\circ} \mathrm{C}$, as shown in Figure 2. The sand specimen was heated to $35^{\circ} \mathrm{C}$ under drained condition for a rate of $5{ }^{\circ} \mathrm{C} / \mathrm{h}$ which was slow enough for the high hydraulic conductivity material. Then, it was followed by a complete mechanical loading-unloading cycle up to $300 \mathrm{kPa}$ and back to $200 \mathrm{kPa}$. Once unloaded, a drained heating phase up to $45{ }^{\circ} \mathrm{C}$ was performed. A mechanical loading-unloading cycle up to $400 \mathrm{kPa}$ and back to $300 \mathrm{kPa}$ was subsequently conducted. Finally, drained heating up to $55^{\circ} \mathrm{C}$ was followed by a final mechanical loadingunloading cycle up to approximately $500 \mathrm{kPa}$ and back to $400 \mathrm{kPa}$. The details of the experimental program are presented in Table 1.

Table 1. Details of the experimental program

\begin{tabular}{|c|c|c|c|c|c|}
\hline Number & $\begin{array}{c}t \\
(\mathrm{~h})\end{array}$ & $\begin{array}{c}\sigma_{3}{ }^{\prime} \\
(\mathrm{kPa})\end{array}$ & $\begin{array}{c}T \\
\left({ }^{\circ} \mathrm{C}\right)\end{array}$ & $\begin{array}{c}\varepsilon_{\mathrm{a}} \\
(\%)\end{array}$ & $\begin{array}{c}\mathcal{E}_{\mathrm{v}} \\
(\%)\end{array}$ \\
\hline 1 & 0 & 0 & 25 & 0 & 0 \\
\hline 2 & 1 & 200 & 25 & 0.777 & 0.748 \\
\hline 3 & 1.5 & 100 & 25 & 0.768 & 0.676 \\
\hline 4 & 3.5 & 100 & 35 & 0.717 & 0.573 \\
\hline 5 & 4.5 & 300 & 35 & 0.861 & 0.812 \\
\hline 6 & 5 & 200 & 35 & 0.846 & 0.769 \\
\hline 7 & 7 & 200 & 45 & 0.802 & 0.512 \\
\hline 8 & 8 & 400 & 45 & 0.919 & 0.687 \\
\hline 9 & 8.5 & 300 & 45 & 0.906 & 0.660 \\
\hline 10 & 10.5 & 300 & 55 & 0.860 & 0.229 \\
\hline
\end{tabular}

\section{Measurement of volume change during heating}

To obtain the actual volume change behavior of saturated sand specimens undergoing temperature changes, a series of calibration tests were conducted on a metallic specimen with the same dimensions as the sand specimens to capture the thermal expansion of the 
apparatus. The metallic specimen was mechanical consolidated to the desired mean effective stresses (i.e., $\left.\sigma_{3}{ }^{\prime}=100 / 200 / 300 \mathrm{kPa}\right)$ while maintaining the temperature constant at $25{ }^{\circ} \mathrm{C}$. Thereafter, a drained heating and cooling cycle (i.e., $T=25-65-25^{\circ} \mathrm{C}$ ) was performed under a constant rate of $5^{\circ} \mathrm{C} / \mathrm{h}$.

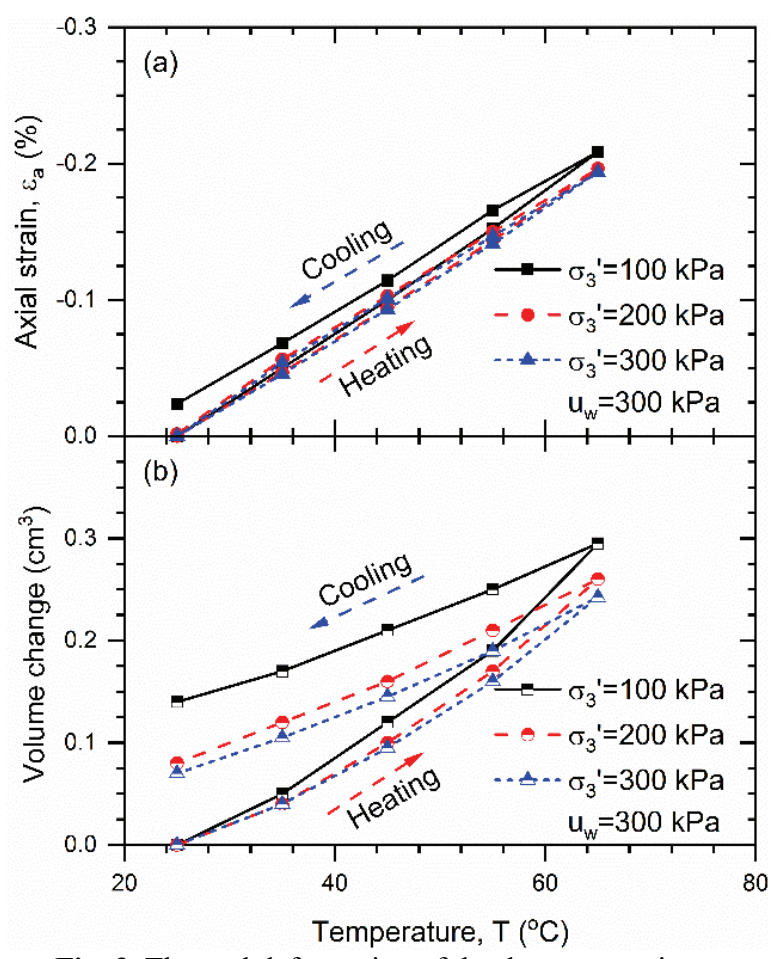

Fig. 3. Thermal deformation of the dummy specimen

During the calibration tests, the irreversible component of axial strain for the metallic specimen undergoing a temperature cycle represents the thermal expansion of the top soil cap and axial rod, and are small enough to be neglected, as shown in Figure 3(a). Thereby, the actual axial strain of the sand specimen can be given as follows:

$$
\varepsilon_{\mathrm{a}}=\frac{\Delta z}{H_{0}} \times 100 \%
$$

where $\varepsilon_{\mathrm{a}}$ is the actual axial strain, $\Delta z$ is the axial displacement which is measured by a linearly variable differential transformer (LVDT) with an accuracy of $0.1 \%, H_{0}$ is the initial height of the sand specimen at the beginning of drained heating phase. The actual volumetric strain of the sand specimen can be defined as follows:

$$
\varepsilon_{\mathrm{v}}=-\frac{\Delta V}{V_{0}} \times 100 \%
$$

where,

$$
\Delta V=\Delta V_{\mathrm{dr}}-\Delta V_{\mathrm{de}}-\Delta V_{\mathrm{w}}-\Delta V_{\mathrm{s}}
$$

$$
\begin{gathered}
\Delta V_{\mathrm{w}}=\beta_{\mathrm{w}}\left(T-T_{0}\right) V_{\mathrm{w}} \\
\Delta V_{\mathrm{s}}=\beta_{\mathrm{s}}\left(T-T_{0}\right) V_{\mathrm{s}}
\end{gathered}
$$

where $\varepsilon_{\mathrm{v}}$ is the actual volumetric strain, $\Delta V$ is the actual volume change of the sand specimen, $V_{0}$ is the initial volume of the sand specimen before drained heating. $\Delta V_{\mathrm{dr}}$ is the volume of water flowing out or into the specimen during drained heating, and can be measured by the backpressure volume controller directly. $\Delta V_{\text {de }}$ is the thermal expansion of the drainage system, which is the irreversible component during a calibration test (as shown in Figure 3(b)), and can be used to correct the observed volume change of sand specimens under drained temperature-controlled tests during each temperature step; $\Delta V_{\mathrm{w}}$ is the thermal expansion of the pore water, $\Delta V_{\mathrm{s}}$ is the thermal expansion of the solid skeleton. $\beta_{\mathrm{w}}$ is the volumetric coefficient of thermal expansion of pore water, $T$ is the target temperature, $T_{0}$ is the room temperature, $V_{\mathrm{w}}$ is the volume of pore water in the specimen after mechanical consolidation. $\beta_{\mathrm{s}}$ is the volumetric coefficient of thermal expansion of solid skeleton and $V_{\mathrm{s}}$ is the volume of the solid skeleton after mechanical compression.

\section{Test Results}

\subsection{Trends in volume of water expelled}

The results of the triaxial compression test performed on the Fujian sand are depicted in Figure 4 in the form of the water expelled from sand specimen versus time curves for all the applied loading-unloading-heating steps. The volume of the water expelled out of the sand specimen is measured by the backpressure volume controller directly. During each loading step, an increase in mean effective stress for a constant temperature leads to an increase in volume of water expelled from the sand specimen, as shown in Fig. 4(a), Fig.4(d) and Fig.4(g).

During each unloading step, the volumes of water expelled are negative, which means that the water flowed into the sand specimen when the applied mean effective stress decreases leading to volumetric expansion of the sand specimen, as shown in Fig. 4(b), Fig. 4(e) and Fig. 4(h). In addition, it also can be seen that the volume of water expelled from the saturated sand specimen for a loading/unloading step (e.g., when mean effective stress increases from $100 \mathrm{kPa}$ to $300 \mathrm{kPa}$, as shown in Fig. 4(d)) is lower than that for the previous loading/unloading step (e.g. when mean effective stress increases from $0 \mathrm{kPa}$ to $200 \mathrm{kPa}$, as shown in Fig. 4(a)). 

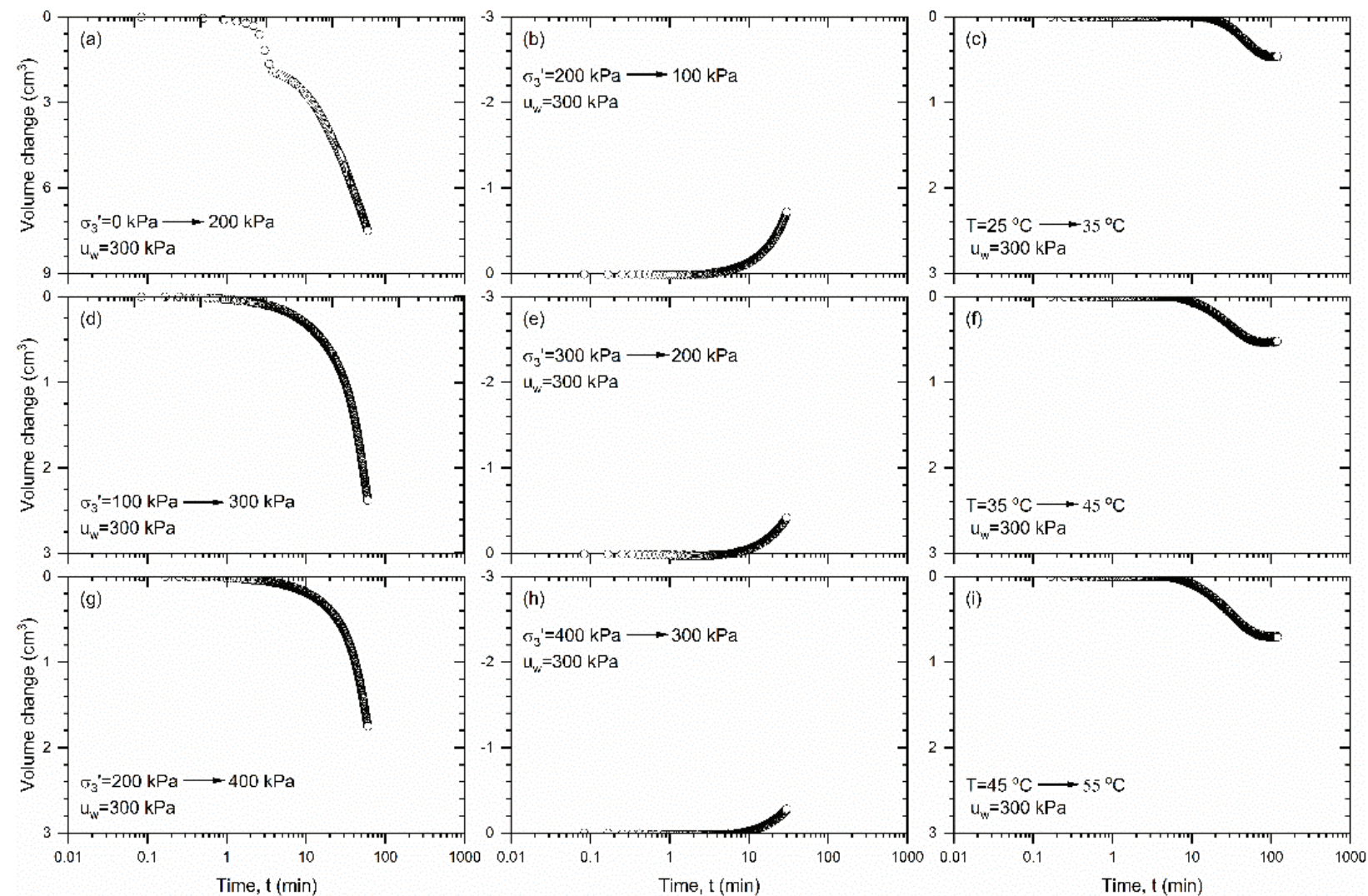

Fig. 4. Time series of water volume expelled from saturated sand specimen during the stages shown in Figure 2

During each drained heating step, the volume of water flowed out of the sand specimens increased with increasing temperature, and then reached a constant value when the temperature reaches equilibrium. This observation may be caused by differences in the volumetric coefficients of thermal expansion of the pore water and solid skeleton of the sand specimen.

\subsection{Trends in thermal axial and volumetric strains}

The measured axial and volumetric strains of the saturated, loose sand specimen after drained loadingunloading-heating phase are shown in Figure 5. The values of the axial and volumetric strains were calculated using Equations (1) and (2), respectively. All the values used in the analysis are listed in Table 1. It can be observed that all the axial and volumetric strains for the loose sand specimen are positive, reflecting contraction, as shown in Fig. 5(c). During mechanical loading phase, the axial strain is positive, and it increases with increasing mean effective stress for a given temperature. In addition, it decreases with the reduction in the mean effective stress during mechanical unloading phase, as shown in Fig. 5(b) and Fig. 5(c). During drained heating phase, an increase in temperature would lead to a decrease in the total positive axial strain, as shown in Fig. 5(a) and Fig. 5(c). It can be also observed that the actual axial strain during mechanical unloading and drained heating phases are negative, reflecting expansion. Due to the negative values of the axial strains during mechanical unloading and drained heating phases, they are less than the positive values of the axial strains during the mechanical loading phase. Accordingly, the total values of the axial strains are positive, and the loose sand specimen occurs contractive behavior.

Similar to the axial strain, the total volumetric strain for loose sand specimen after loading-unloading-heating phase is positive, reflecting compression volumetrically, as shown in Fig. 5(c). The relationship between axial and volumetric strains and temperature are shown in Figure 6. In addition, $\mathrm{Ng}$ et al. [28] found out that the thermal volumetric strain of loose, saturated sand specimen $\left(D_{\mathrm{r}}\right.$ $=21 \%$ ) was positive, reflecting compression. However, this behavior was not observed in this study. This difference may be caused by the OCR of sand specimen. The sand specimen was consolidated, and then heated to the target temperature. In their experiment, there were mechanical loading and drained heating, nor a mechanical unloading phase. Moreover, Liu et al. [29] proposed that the bulk thermal expansion coefficient increased with increasing relative density for sand or OCR for clay. 


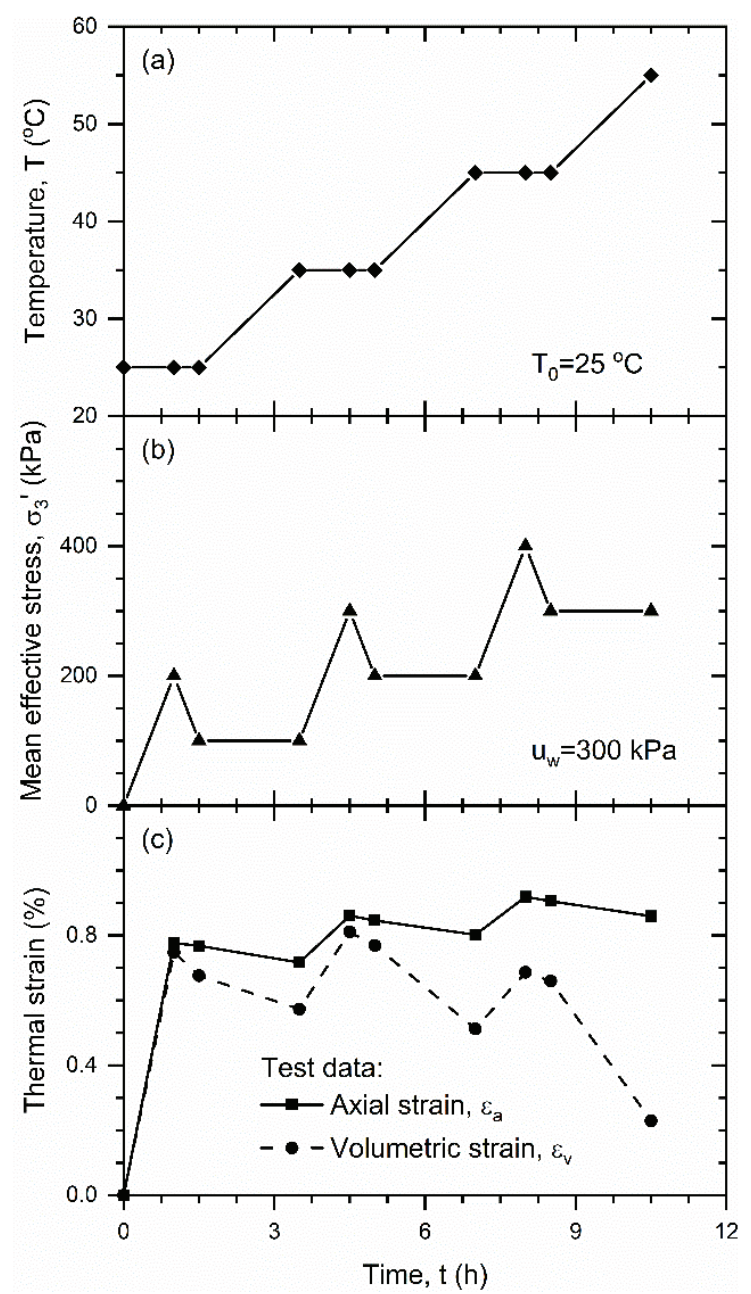

Fig. 5. Time series of thermal strain, mean effective stress and temperature for the loose saturated sand specimen

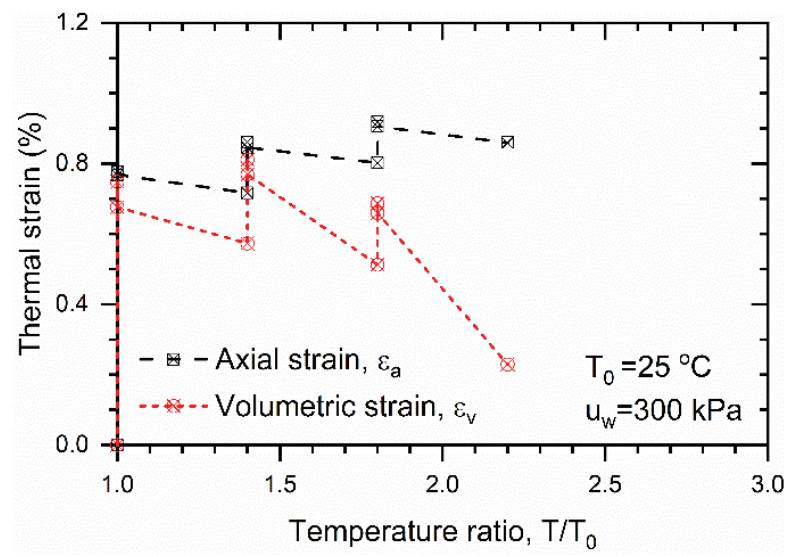

Fig. 6. Relationship between temperature and strains for the three stages

For loose sand, the bulk thermal expansion coefficient was positive, and the specimen would be contractive in the conventional temperature-controlled triaxial tests. For highly overconsolidated clay, the bulk thermal expansion coefficient was negative, and the specimen would be expansion. In this study, the sand specimen is loose, but it had underwent mechanical loading and unloading before it was heated (similar to the effects of OCR on clays or silts). During drained heating, the loose sand specimen experiences expansive behavior as a joint result of relative density and the mechanical loading-unloading effects.

\section{Conclusions}

A series of temperature-controlled hollow triaxial compression tests were carried out to capture the volume change behavior of saturated, loose sand specimen during mechanical loading-unloading-heating phase. In the calibration test, some permanent thermal expansions were observed that were critical to consider in processing the results from the experiments on sand. The axial and volumetric strains during mechanical unloading phase and drained heating phase were negative, reflecting expansion. The thermal expansion behavior for loose sand was due to the joint result of relative and OCR. The total expansion during these two phases was smaller than the compression during mechanical loading phase. Furthermore, the total values of axial and volumetric strains were positive, reflecting compression.

The authors would like to acknowledge the financial support from the Project supported by the National Natural Science Foundation of China (Grant No. 51678094), Scientific Research Founding Project of Neijiang Normal University (Grant No. 2019FM02).

\section{References}

[1] Mimouni T, Laloui L. Behaviour of a group of energy piles. Can Geotech J 2015; 52(12): 1913-1929.

[2] Moel Md, Bach PM, Bouazza A, Singh RM, Sun JO. Technological advances and applications of geothermal energy pile foundations and their feasibility in australia. Renewable Sustainable Energy Rev 2010; 14(9): 2683-2696.

[3] Bourne-Webb PJ, Amatya B, Soga K, Amis T, Davidson C, Payne P. Energy pile test at lambeth college, london-geotechnical and thermodynamic aspects of pile response to heat cycles. Geotechnique 2009; 59(3): 237-248.

[4] Başer T, Lu N, McCartney JS. Operational response of a soil-borehole thermal energy storage system. J Geotech Geoenviron 2016; 142(4): 04015097.

[5] Murphy KD, McCartney JS, Henry KS. Evaluation of thermo-mechanical and thermal behavior of fullscale energy foundations. Acta Geotech 2014; 10(2): 179-195.

[6] Gao J, Zhang X, Liu J, Li K, Yang J. Numerical and experimental assessment of thermal performance of 
vertical energy piles: An application. Appl Energ 2008; 85(10): 901-910.

[7] Liu H-1, Wang C-1, Kong G-q, Ng CWW, Che P. Model tests on thermo-mechanical behavior of an improved energy pile. European Journal of Environmental and Civil Engineering 2017: 1-16.

[8] Stewart, M. A., Coccia, C. J. R., and McCartney, J. S. (2014). "Issues in the Implementation of Sustainable Heat Exchange Technologies in Reinforced, Unsaturated Soil Structures." Proceedings of GeoCongress 2014 (GSP 234), 4066-4075.

[9] Fadejev J, Simson R, Kurnitski J, Haghighat F. A review on energy piles design, sizing and modelling. Energy 2017; 122: 390-407.

[10] Knellwolf C, Peron H, Laloui L. Geotechnical analysis of heat exchanger piles. J Geotech Geoenviron 2011; 137(10): 890-902.

[11] Wang C-1, Liu H-1, Kong G-q, Ng CWW, Wu D. Model tests of energy piles with and without a vertical load. Environmental Geotechnics 2016; 3(4): 203-213.

[12] Brandl H. Energy foundations and other thermoavtive ground structures. Geotechnique 2006; 56(2): 81-122.

[13] Coccia CJR, McCartney JS. Impact of heat exchange on the thermo-hydro-mechanical response of reinforced embankments. Proceedings of GeoCongress 2013, ASCE 2013; (3-5): 343-352.

[14] Croll JGA. The role of thermal ratcheting in pavement failures. Proceedings of the Institution of Civil Engineers - Civil Engineering 2009; 162(3): 127-140.

[15] Kertesz R, Sansalone J. Hydrologic transport of thermal energy from pavement. J Environ Eng 2014; 140(8): 04014028.

[16] Abuel-Naga HM, Bergado DT, Ramana GV, Grino L, Rujivipat P, Thet Y. Experimental evaluation of engineering behavior of soft bangkok clay under elevated temperature. Journal of Geotechnical and Geoenvironment Engineering 2006; 132(7): 902910.

[17] Baldi G, Hueckel T, Pellegrini R. Thermal volume changes of the mineral-water system in low- porosity clay soils. Can Geotech J 1988; 25(4): $807-$ 825.

[18] Cekerevac C, Laloui L. Experimental study of thermal effects on the mechanical behaviour of a clay. Int J Numer Anal Met 2004; 28(3): 209-228.

[19] Ng CWW, Zhou C. Cyclic behaviour of an unsaturated silt at various suctions and temperatures. Geotechnique 2014; 64(9): 709-720.

[20] Romero E, Villar MV, Lloret A. Thermo-hydromechanical behaviour of two heavily overconsolidated clays. Eng Geol 2005; 81(3): 255 268.

[21] Soleimanbeigi A, Edil TB, Benson CH. Effect of temperature on geotechnical properties of recycled asphalt shingle mixtures. Journal of Geotechnical and Geoenvironment Engineering 2014; 141(2): 04014097.

[22] Uchaipichat A, Khalili N. Experimental investigation of thermo-hydro-mechanical behaviour of an unsaturated silt. Geotechnique 2009; 59(4): 339-353.

[23] Vega A, McCartney JS. Cyclic heating effects on thermal volume change of silt. Environmental Geotechnics 2015; 2(5): 257-268.

[24] Zhou C, Ng CWW. Effects of temperature and suction on plastic deformation of unsatured silt under cyclic loads. J Mater Civil Eng 2016; 28(12): 04016170.

[25] Burghignoli A, Desideri A, Miliziano S. A laboratory study on the thermomechanical behaviour of clayey soils. Can Geotech J 2000; 37(4): 764-780.

[26] Ng CWW, Wang SH, Zhou C. Volume change behaviour of saturated sand under thermal cycles. Geotechnique Letters 2016; 6: 1-8.

[27] Liu H, Liu HL, Xiao Y, McCartney JS. Influence of temperature on the volume change behavior of saturated sand. Geotech Test J 2018; 41(4): 20160308.

[28] D2487 A. Standard practice for classification of soils for engineering purposes (unified soil classification system). ASTM International, West Conshohocken, PA 2011. 